\title{
Avaliação da eficácia terapêutica da ivermectina sobre larvas de quarto estádio de Lagochilascaris minor em gatos infectados experimentalmente
}

\author{
Assessment of ivermectin therapeutic efficacy on fourth-stage larvae \\ of Lagochilascaris minor in experimentally infected cats
}

\section{Carlos Augusto Lopes Barbosa ${ }^{1}$ e Dulcinéa Maria Barbosa Campos}

\begin{abstract}
Resumo Avaliou-se a ação da ivermectina sobre larvas de quarto estádio em gatos infectados experimentalmente com Lagochilascaris minor. Foram utilizados 30 gatos (divididos, igualmente, em três grupos I, II e III), sendo que cada animal foi inoculado, por via oral, com 50 larvas de terceiro estádio do parasito. Cada animal, dos grupos I e II, foi tratado com ivermectina na dosagen de $200 \mu \mathrm{g} / \mathrm{kg}$, no quinto dia após o inóculo (DAI). Os animais do grupo I foram examinados, clinicamente, entre 30 e 40 dias e os do grupo II entre 180 e 190 dias sendo, em seguida, submetidos à necropsia. Os dez animais do grupo III, não foram tratados com a droga constituindo o grupo controle. Independentemente do período de observação, observou-se $100 \%$ de eficácia da droga, visto que houve total interrupção do ciclo biológico do parasito em todos animais tratados. Todos animais do grupo controle desenvolveram a infecção por Lagochilascaris minor.
\end{abstract}

Palavras-chaves: Ivermectina. Lagochilascaris minor. Larvas de quarto estádio.

Abstract In order to verify the action of ivermectin against fourth-stage larvae of Lagochilascaris minor, thirty cats were divided into three groups (I, II and III). Each animal was inoculated orally with 50 third-stage larvae. The cats from groups I and II were treated with Ivermectin $(200 / \mu \mathrm{g} / \mathrm{kg} / \mathrm{single} \mathrm{dose} / \mathrm{sc}$ via) on fifth day after inoculation (DAI). Treatment evaluation was performed between 30 and 40 DAI (group I) and between 180 to 190 DAI (group II) using parasite macroscopic and microscopic research at autopsy. The 10 cats from group III were untreated (control group). The authors observed 100\% drug efficacy, at all observation periods, by total interruption of parasite's biological cycle in each of the treated animals. All the control group developed Lagochilascaris minor infection.

Key-words: Ivermectina. Lagochilascaris minor. Fourth-stage larvae.

A reprodução completa do ciclo biológico de Lagochilacaris minor utilizando hospedeiros experimentais realizada por Campos et $\mathrm{al}^{78}$, permitiu o estudo detalhado da biologia do parasito. No ciclo evolutivo experimental observa-se que, em camundongos inoculados com ovos infectantes do parasito, por via oral, as larvas de terceiro estádio do interior dos ovos eclodem na luz intestinal e são distribuídas para todo organismo através da circulação sistêmica, encistando-se especialmente na musculatura esquelética e tecido subcutâneo $0^{8}$. Quando gatos são alimentados com carcaças de camundongos infectados observa-se a continuidade do ciclo evolutivo do parasito. Nestes hospedeiros, as larvas de terceiro estádio ascendem pelo trato digestivo até a orofaringe e larvas de quarto estádio são vistas do segundo ao oitavo dia, atingindo a fase adulta entre nove e quinze dias após a infecção, em tecidos da rino e orofaringe, tecido subcutâneo da região cervical, ouvido, seios nasais e face ${ }^{8}$.

Há na literatura, registros de insucesso no tratamento da lagochilascaríase humana após o uso de derivados benzimidazólicos 159141517181920 .

A manutenção do parasito em laboratório tem possibilitado a realização de ensaios farmacológicos ${ }^{234}$ visando eficácia na terapêutica da doença. Resultados satisfatórios com o uso da Ivermectina (IVT) em várias nematodioses ${ }^{10} 1213$ estimularam avaliar, na oportunidade, a eficácia terapêutica desta droga sobre larvas de quarto estádio de L. minor.

\footnotetext{
1. Depatamento de Microbiologia, Imunologia, Parasitologia e Patologia do Instituto de Patologia Tropical e Saúde Pública da Universidade Fedral de Goiânia, GO

Endereço para correspondência:Dr. Carlos Augusto Lopes Barbosa. DMIPP/IPTSP/UFG. R. Delenda Rezende de Mello s/n Esq. Iª Avenida. Setor Universitário. 75605-050 Goiânia, GO.

Tel: 5562 259-4111/209-6114

Recebido para publicação em 16/6/2000.
} 


\section{MATERIAL E MÉTODOS}

Isolado de L. minor. Ovos e larvas de $3^{\circ}$ estádio necessários para inoculação de camundongos e gatos, respectivamente, hospedeiros intermediários e definitivos do verme, foram obtidos conforme Campos et $\mathrm{al}^{8}$ e Barbosa et $\mathrm{al}^{4}$.

Camundongos e vias de inoculação. Foram utilizados 40 camundongos isogênicos da linhagem C57BL/6 inoculados, cada um, por via oral com aproximadamente 1.000 ovos do parasito ${ }^{4}$.

Gatos e vias de inoculação. Foram utilizados 30 gatos domésticos, de diferentes procedências com aproximadamente seis meses de idade divididos em três grupos iguais (I, II e III). Após um jejum de aproximadamente 15 horas, cada animal, foi alimentado com carcaças de camundongos contendo cerca de 50 larvas de terceiro estádio encistadas nos tecidos ${ }^{4}{ }^{8}$.

Droga. Utilizou-se a ivermectina, derivado do avermectin B 22,23 dihidro, uma lactona macrocíclica produzida pelo actinomiceto Streptomyces avermectilis, com nome comercial de Ivomec ${ }^{6}{ }^{10}$. A droga foi diluída com propilenoglicol e administrada por via subcutânea na dosagem de $200 \mu \mathrm{g} / \mathrm{kg}$ por animal.

Tratamento com IVT e avaliação da eficácia terapêutica da droga. Gatos infectados com larvas de $3^{\circ}$ estádio de $L$. minor, apresentam no $5^{\circ}$ dia após a infecção (DAI), quase que exclusivamente larvas de quarto estádio, localizadas no rino e orofaringe ${ }^{7}$. Por essa razão, cada animal dos grupos I e II foi tratado com IVT/200 $\mu \mathrm{g} / \mathrm{Kg} /$ dose única, no quinto dia após a inoculação (DAI). Os dez animais do subgrupo III não foram tratados com a droga (grupo controle). Os animais do grupo I foram acompanhados entre 30 e 40 dias após o tratamento (DAT). Tendo em vista a possibilidade de ocorrência do ciclo auto-infectante do helminto, os animais do subgrupo II foram acompanhados durante o período de 180 e 190 dias após o tratamento (DAT). Todos os animais foram submetidos aos exames clínico e coproparasitológico. As necropsias e pesquisa de estádios evolutivos do parasito foram feitas, dentro de um intervalo de dez dias, a partir de 30 DAT entre os animais do grupo I e a partir de 180 DAT entre aqueles do grupo II. Para os animais do grupo III, programouse as necropsias de cinco deles a partir do 30 DAT e o restante a partir do $180^{\circ}$ DAT. Alguns foram necropsiados conforme o período de sobrevivência.

Necrópsias. Todas as necropsias foram realizadas conforme previamente descrito ${ }^{278}$.

Análise microscópica. Os parasitos coletados durante as necropsias foram fixados em formol a $10 \%$, clarificados em ácido acético, diafanizados em creosoto de Faia e identificados através de microscopia óptica.

\section{RESULTADOS}

Entre os gatos tratados com a droga na dosagem de $200 \mu \mathrm{g} / \mathrm{Kg}$ no quinto DAl e acompanhados durante o período de 30-40 DAT (grupo I) e 180-90 DAT (grupo II) observou-se a total interrupção do ciclo biológico do parasita. Não foram evidenciadas lesões na superfície cutânea e os exames coproparasitológicos foram negativos durante todo o período de observação. Da mesma forma, não foi recuperado qualquer estádio evolutivo do parasito após as necropsias.

Entre os animais do grupo controle houve 100\% de positividade à infecção por L. minor. Do total de 10 animais, $75 \%$ apresentaram exames coproparasitológicos positivos e $25 \%$ negativos. O exame parasitológico de fezes tornou-se positivo a partir do15 DAl.

Entre os animais que apresentaram exames coproparasitológicos negativos, a infecção foi diagnosticada pela presença de lesões contendo o parasita nas seguintes localizações: orofaringe, sistema nervoso central, região cervical, submandibular, mandíbula e tecido subcutâneo da cabeça. Regra geral, em lesões localizadas na região cervical e orofaringe, observou-se a formação de pertuitos com eliminação de ovos para a luz do tubo digestivo justificando o encontro de ovos nas fezes destes animais indicando, ainda, comunicação do tecido subcutâneo e da orofaringe por meio de fístulas ou verdadeiros túneis nos tecidos.

Os percentuais referentes à localização das lesões em gatos do grupo controle, foram os seguintes: orofaringe $(45 \%)$, região cervical $(30 \%)$, mandíbula (10\%), SNC (5\%), região submandibular $(5 \%)$, e tecido subcutâneo da cabeça (5\%). Observou-se $40 \%$ de mortalidade entre os animais do grupo controle. Nesses casos, as necropsias foram antecipadas, tendo em vista o grau de comprometimento do estado físico dos animais.

\section{DISCUSSÃO}

Vários anti-helmínticos têm sido utilizados em pacientes com lagochilascaríase, visando a cura definitiva da doença, porém a grande maioria dos esquemas terapêuticos empregados tem se revertido em insucesso. Tanto na lagochilascaríase humana como em infecções experimentais, tem-se observado a presença de todas as fases do ciclo evolutivo do parasito no local do abcesso ${ }^{13} 78914$. Esse fenômeno, ou seja, ocorrência do ciclo auto-infectante de L. minor tem contribuindo para dificultar a terapêutica, na lagochilascaríase 278 . Face à esta peculiaridade no ciclo evolutivo deste parasito, uma droga ideal terá que apresentar eficácia sobre todas as fases do seu ciclo evolutivo isto é, terá que ser ovicida, larvicida e vermicida ${ }^{2} 348$.

Os derivados bezimidazólicos são as drogas mais comumente empregadas no tratamento da lagochilascaríase humana. Admite-se que o tiabendazol e levamisol possuam ação vermicida e possivelmente 
larvicida não exercendo porém ação ovicida. Atribui-se ao albendazol uma ação ovicida porém, ensaios terapêuticos realizados por Vieira et $a^{21}$ demonstraram que embora impeça a embriogênese de ovos, esta droga é ineficaz sobre larvas no interior de ovos de L. minor.

Na oportunidade, optou-se pelo uso da ivermectina, devido sua eficácia sobre vários helmintos, sobretudo nematódeos, em diversas fases evolutivas, e em diferentes hospedeiros. Seu uso tem sido registrado, tanto em medicina veterinária quanto humana. A eficácia desta droga foi demonstrada no tratamento de infecções por vários vermes pulmonares em ovinos, eqüinos e suínos ${ }^{6}$. Em camundongos, foi eficaz contra larvas filarióides e vermes adultos de Strongyloides ratti e S. stercoralis ${ }^{11}$. No homem, quando utilizada nas dosagens de 50 a $200 \mu \mathrm{g} / \mathrm{kg}$ observaram-se índices de eficácia terapêutica de $88 \%$ para estrongiloidíase, $100 \%$ para ascaridíase, $85 \%$ para trichuríase e $85 \%$ para enterobiose ${ }^{16}$. Barbosa et $\mathrm{al}^{4}$ e Barbosa e Campos $^{3}$ realizaram testes terapêuticos visando avaliar a eficácia da ivermectina sobre ovos e larvas de terceiro estádio de L. minor. Estes autores observaram que a IVT na concentração de $200 \mu \mathrm{g}$ por litro de formalina a $1 \%$, durante 28 dias in vitro, não impediu o processo de embriogênese e nem desvitalizou larvas do interior de ovos de L. minor. Observaram, ainda, $99,5 \%$ de eficácia da droga na dosagem de $1.000 \mu \mathrm{g} / \mathrm{kg}$ sobre larvas de 3 o estádio em fase de migração e eficácia inferior a 5\% sobre larvas de 3 estádio encistadas em tecidos de camundongos infectados. Na dosgem de $200 \mu \mathrm{g} / \mathrm{kg}$ observaram ineficácia da droga tanto sobre larvas de 3 o estádio em migração quanto larvas $3^{\circ}$ estádio encistadas.

Não obstante, os resultados anteriormente obtidos com IVT na dosagem de $200 \mu \mathrm{g} / \mathrm{kg}$ sobre de larvas de 3 ํㅡ estádio em camundongos decidiu-se avaliar da eficácia da mesma sobre larvas de quarto estádio em gatos hospedeiros definitivos experimentais, devido a semelhança entre a infecção humana e nestes animais. Tanto no hospedeiro defintivo experimental com no hospedeiro humano observam-se lesões, principalmente, no tecido subcutâneo da região cervical, sistema nervoso central, conduto auditivo, nos seios nasais e na orofaringe ${ }^{78}$.

Os resultados de $100 \%$ de eficácia terapêutica da IVT observados, na oportunidade, demonstram que a droga atua sobre as larvas de $4^{\circ}$ estádio bloqueando o desenvolvimento de larvas de quarto estádio para vermes adultos de L. minor. Embora esses resultados possam afigurar-se como animadores, acredita-se que a cura definitiva na lagochilascaríase com o uso da IVT exija o emprego de um esquema terapêutico com múltiplas doses tendo em vista sua ineficácia sobre outros estádios do ciclo evolutivo do verme.

\section{REFERÊNCIAS BIBLIOGRÁFICAS*}

1. Baracat DA, Freire EL, Aquino JL. Oto-mastoidite crônica por Lagochilascaris minor com comprometimento da região têmporoparieto-occipital. Revista da Universidade Federal do Mato Grosso 2: 9-14, 1984.

2. Barbosa CAL, Vieira MA, Campos DMB, Oliveira JA. Recidiva múltipla de lesão após tratamento com ivermectin em gato experimentalmente infectado com Lagochilascaris minor. In: Resumos do XII Congresso Latino-Americano de Parasitologia, Chile, 1995.

3. Barbosa CAL, Campos DMB, Oliveira JA. Assessment of ivermectin therapeutic efficacy on third-stage larvae of Lagochilascaris minor in mice experimentally infected. Revista do Instituto de Medicina Tropical de São Paulo 40:137-143, 1998.

4. Barbosa CAL, Campos DMB, Oliveira JA, Vieira MA. Avaliação in vitro da atividade ovicida e larvicida da ivermectina sobre Lagochilascaris minor. Revista de Patologia Tropical 26:57-68, 1997.

5. Borgo AV, Andrade ALS, Pedrosa RB, Barbosa W, Komma MD. Infecção por Lagochilascaris minor - apresentação de caso. In: Resumos do XIV Congresso da Sociedade Brasileira de Medicina Tropical e X Congresso da Sociedade Brasileira de Parasitologia João Pessoa p. 391, 1978.

6. Campbell WC. Ivermectin: an update. Parasitology Today 1: 10 $16,1985$.

7. Campos DMB, Barbosa CAL, Paçô JM. Ocorrência do ciclo autoinfectante na lagochilascaríase felina experimental. Revista Brasileira de Parasitologia Veterinaria 2: 60,1993.
8. Campos DMB, Freire- Filha LG, Vieira MA, Paço JM, Maia MA. Experimental life cycle of Lagochilascaris minor Leiper, 1909. Revista do Instituto de Medicina Tropical de São Paulo 34: 27787, 1992.

9. Draper JW, Buckley JJC. Lagochilascaris minor Leiper, 1909, from a patient in Tobago. Transactions of the Royal Society of Tropical Medicine and Hygiene 57: 7, 1963.

10. Egerton JR, Birbaum J, Blair LS, Chabala JC, Conroy J, Fisher $\mathrm{MH}$, Mrozik H, Ostlind DA, Wilkins CA, Campbell WC. 22,23dihidroavermectin b1, a new broad-spectrum antiparasitic agent. British Veterinary Journal 136: 88,1980.

11. Grove DI. The effects of 22,23 - dihidro avermectin B1 on Strongyloides ratti and $S$. stercoralis infection in mice. Animals of Tropical Medicine and Parasitology. 4:705-710, 1983.

12. Guerrero J. Use of ivermectin in humans. Technical Bulletin/World Health Organization p.89-93, 1993.

13. Kumaraswami V, Ottesen EA, Vijayasekaran V, Devi SU, Swaminathan M, Aziz MA, Sarma GR, Prabhakar R, Tripathy SP. Ivermectin for the treatment of Wuchereria bancrofti filariasis. Efficacy and adverse reactions. Journal of Amarican Medicine Association 21: 3150-3154,1988.

14. Leão RNQ, Leão-Filho J, DIAS LB, Calheiros LB. Infecção humana pelo Lagochilascaris minor Leiper, 1909. Registro de um caso observado no Estado do Pará (Brasil). Revista do Instituto de Medicina Tropical de São Paulo 20: 300-306, 1978.

15. Moraes MAP, Arnaud MVC, Lima PE. Novos casos de infecção humana por Lagochilascaris minor Leiper, 1909 encontrados no Estado do Pará, Brasil. Revista do Instituto de Medicina Tropical de São Paulo 25: 139-146, 1983. 
16. Naquira C, Jimenez G, Guerra JG, Bernal R, Nalin DR, Neu D, Aziz M. Ivermectin for human strongyloidiasis and other intestinal helminths. The American Journal of Tropical Medicine and Hygiene 40: 304-309,1989.

17. Oostburg BFJ. The sixth case of Lagochilascaris minor in Surinam. Tropical and Geographic Medicine 1:154-159, 1992.

18. Oostburg BFJ, Varma AAO. Lagochilascaris minor infection in Surinam, report of a case. The American Journal of Tropical Medicine and Hygiene 17: 548-550,1968.

19. Orihuela R, Botto C, Delgado O, Ortiz A, Suarez JA, Arguello C. Lagochilascaríasis humana en Venezuela: descripción de un caso fatal. Revista da Sociedade Brasileira de Medicina Tropical 20: 217-221, 1987.

20. Rocha MPC, Fraiha -Neto H, Barreto -Netto ACP. Infecção de ouvido médio e mastóide por Lagochilascaris minor Leiper, 1909 (Nematoda, Ascaridiae). Relato de um caso do Sul do Estado do Pará, Amazônia, Brasil. Hiléia Médica 6: 3-14, 1984.

21. Vieira MA, Oliveira JA, Barbosa CAL. Avaliação da eficácia do albendazol na lagochilascaríase murina experimental. Revista de Patologia Tropical 25: 253-262,1996. 